\section{The role of epigenetics in age-related macular degeneration}

M Gemenetzi ${ }^{1}$ and AJ Lotery ${ }^{1,2}$

\begin{abstract}
It is becoming increasingly evident that epigenetic mechanisms influence gene expression and can explain how interactions between genetics and the environment result in particular phenotypes during development. The extent to which this epigenetic effect contributes to phenotype heritability in age-related macular degeneration (AMD) is currently ill defined. However, emerging evidence suggests that epigenetic changes are relevant to AMD and as such provide an exciting new avenue of research for AMD. This review addresses information on the impact of posttranslational modification of the genome on the pathogenesis of AMD, such as DNA methylation changes affecting antioxidant gene expression, hypoxia-regulated alterations in chromatin structure, and histone acetylation status in relation to angiogenesis and inflammation. It also contains information on the role of non-coding RNA-mediated gene regulation in AMD at a posttranscriptional (before translation) level. Our aim was to review the epigenetic mechanisms that cause heritable changes in gene activity without changing the DNA sequence. We also describe some long-term alterations in the transcriptional potential of a cell, which are not necessarily heritable but remains to be defined in the future. Increasing understanding of the significance of common and rare genetic

genetics'. The headline used to locate related articles in PubMed was 'epigenetics in ocular disease', and to restrict search, we used the headlines 'DNA methylation in age related macular degeneration', 'altered gene expression in AMD pathogenesis'. A manual search was also based on references from these articles as well as review articles.

Eye (2014) 28, 1407-1417; doi:10.1038/eye.2014.225; published online 19 September 2014

\section{Introduction}

Epigenetic mechanisms may have a pathogenic role in many complex eye diseases such as keratitis, amblyopia, myopia, cataract, glaucoma, proliferative vitreoretinopathy, diabetic retinopathy, retinitis pigmentosa, uveal melanoma, retinoblastoma, and age-related macular degeneration (AMD). ${ }^{1}$

The pathogenesis of AMD involves genetic and environmental influences. The former consists of common and rare genetic, copy number and mitochondrial sequence variations and epigenetics. ${ }^{2}$ The latter includes smoking, obesity, and dietary factors such as antioxidants and dietary fat intake. ${ }^{3}$ As such AMD is a complex, multifactorial disease. These risk factors result in pathologic responses such as inflammation, ischemia, and vascular remodeling, as well as neurodegeneration. ${ }^{4-6}$
\end{abstract} variants and their relationship to epigenetics and environmental influences may help in establishing methods to assess the risk of AMD. This in turn may allow new therapeutic interventions for the leading cause of central vision impairment in patients over the age of 50 years in developed countries.

Search strategy

We searched the MEDLINE/PubMed database following MeSH suggestions for articles including the terms: 'ocular epigenetic mechanisms', 'human disease epigenetics', and 'age-related macular degeneration

\section{So where does epigenetics fit in?}

Epigenetics is defined as the study of covalent modification of the genome that alters structure and function but not gene sequence. ${ }^{7}$

Epigenetics describes a means by which genes are either turned on or turned off by a heritable epigenome. ${ }^{8}$ Usually, we inherit two copies of one gene, one from each parent, however, if one of those copies is epigenetically shut off and the remaining working gene is deleted or severely mutated, the phenotype changes. For example,
${ }^{1}$ Southampton Eye Unit, Southampton University Hospital, Southampton, UK

${ }^{2} \mathrm{Clinical}$ and Experimental Sciences, Faculty of Medicine, University of Southampton, University Hospital Southampton, Southampton, UK

Correspondence: AJ Lotery, Clinical and Experimental Sciences, Faculty of Medicine, University of Southampton, South Lab and Path Block, Mailpoint 806, Level D, University Hospital Southampton, Southampton SO16 6YD, UK

Tel: +44 (0)23 8079 4590/ 5049;

Fax: +44 (0)23 8079 4264/ 4542.

E-mail: a.j.lotery@

soton.ac.uk

Received: 10 March 2014 Accepted in revised form: 31 July 2014

Published online:

19 September 2014 
Angelman syndrome is a nervous system disorder caused by the turning off (genetic imprinting) of the normally expressed maternal gene by deletion in chromosome 15. Its 'sister' disorder called Prader-Willi syndrome is caused by the loss of the paternal contribution of another gene in the same region of chromosome 15. In each case, the presence of a second normal (wild-type) copy of the gene(s) on the methylated, tightly packed copy of chromosome 15 is of no use in correcting the defect. ${ }^{9}$ Epigenetic mechanisms influence gene expression and explain how interactions between genetics and environment can give rise to phenotypes during development. ${ }^{10}$ One example is the much stronger effect of sunlight exposure on skin cancer risk in fair-skinned humans than in individuals with darker skin or the flushing response seen after alcohol ingestion in individuals with low-activity polymorphisms in the aldehyde dehydrogenase gene. ${ }^{11}$

Epigenetic mechanisms comprise DNA methylation, histone modification, chromatin remodeling, non-coding RNA-mediated gene silencing, and other mechanisms involved in generating and maintaining heritable chromatin structure and attachment to the nuclear matrix. $^{12}$

Genome-wide association studies have identified major common susceptibility genetic variants, but they have failed to explain the complete genetic heritability in complex diseases. ${ }^{13}$ What remains to be explained regarding the origin of the disease at a molecular level is often referred to as 'missing heritability'. Exploring the operation of the epigenetic 'machinery' may shed some light on what is called the 'dark matter of the genome'.

Disruption of the epigenome is a fundamental mechanism in a number of cancers, and several epigenetic drugs that have proved to prolong survival and to be less toxic than conventional chemotherapy have been recently approved for cancer treatment. ${ }^{14}$ Likewise, the understanding of the significance of common and rare genetic variants and their relationship to epigenetics and environmental influences may help in establishing methods to assess the risk of AMD and plan new therapeutic interventions for the leading cause of central vision impairment in patients over the age of 50 years in developed countries. ${ }^{6}$

\section{DNA methylation and histone acetylation in AMD}

DNA methylation in vertebrates typically occurs in cytosine-phosphate-guanine (CpG) sites, where a cytosine is directly followed by a guanine in the DNA sequence and it results in the conversion of the cytosine to 5-methylcytosine. The formation of Me-CpG is catalyzed by the enzyme DNA methyltransferase (DNMT). The modification of DNA by the addition of a methyl group to cytosine changes the electrostatic nature of chromatin. ${ }^{15,16}$ The overall methylation state in a cell might be a precipitating factor in carcinogenesis as evidence suggests that genome-wide hypomethylation can lead to chromosome instability and increased mutation rates. ${ }^{17}$ In general, CpG methylation silences genes, whereas demethylation activates them, although recent studies have shown that the functional effects of DNA methylation can vary according to the genomic context. $^{18}$

Histones that are protein components of chromatin act as spools around which DNA winds and this enables large genomes of eukaryotes fit inside the cell nuclei. Histone acetylation and deacetylation are essential parts of gene regulation. Histone acetylation is associated with transcriptional activation, whereas deacetylated histones are associated with transcriptional repression. ${ }^{19}$

\section{DNA methylation changes affect antioxidant gene expression in AMD}

Although the cause of AMD is incompletely understood, there is evidence that oxidative stress is involved. Antioxidant vitamins can slow the progression in moderate to advanced AMD. ${ }^{20}$ Patients with AMD appear to have a reduced serum antioxidant potential, which is partially alleviated by vitamin supplementation. ${ }^{21,22}$ Further, smoking, a potent oxidative insult, is the most important environmental risk factor for AMD. ${ }^{23-27}$ Damaging proteins, lipids, and free radicals can influence chromatin structure. To assess the potential contribution of epigenetic regulation of antioxidant genes relevant to AMD pathogenesis, Hunter et $a l^{28}$ evaluated DNA methylation and the way it affects gene expression. Glutathione S-transferase PI (GSTP1) is a scavenger of reactive oxygen species (ROS) and its absence could reduce protection from genome-damaging oxidants, resulting in increased vulnerability to further oxidative insults. Hunter et $a l^{28}$ found that mRNA levels of glutathione S-transferase isoforms mu1 (GSTM1) and mu5 (GSTM5) were significantly reduced in AMD patients vs age-matched controls in retinal pigment epithelium (RPE)/choroid and neurosensory retina. This corresponded to hypermethylation of the GSTM5 promoter. mRNA and protein levels were decreased in the RPE to a greater extent than the neurosensory retina in AMD post-mortem samples, irrespective of age. They concluded that comparison of DNA methylation, together with mRNA levels, revealed significant differences between AMD vs normal retinas. This suggests that GSTM1 and GSTM5 undergo epigenetic repression in AMD RPE/choroid, which may increase susceptibility to oxidative stress in AMD retinas. 
The interleukin 17 receptor C (IL17RC) gene serves as an essential subunit of the IL-17 receptor complex that mediates the signal transduction and proinflammatory activities of $I L-17 A$ and $I L-17 F$. Wei et al ${ }^{29}$ assessed whether methylation changes could be identified through the analysis of twin pairs as these provide a means of dissecting apart genetic and environmental components of disease. In this study, they initially investigated genome-wide differences in DNA methylation patterns between twins (both monozygotic and dizygotic) with discordant AMD and further validated methylation changes identified at the IL17RC promoter in discordant siblings for AMD as well as in an AMD case-control cohort where cases presented with either the dry or the wet form of AMD. Furthermore, they evaluated IL17RC expression in the eyes and blood of AMD patients.

They showed a significantly decreased level of methylation on the IL17RC promoter in AMD patients. Further, they showed that hypomethylation of the IL17RC promoter in AMD patients led to an elevated expression of its protein and mRNA in peripheral blood as well as in the affected retina and choroid, suggesting that the DNA methylation pattern and expression of IL17RC may potentially serve as a biomarker for the diagnosis of AMD and likely have a role in disease pathogenesis. Their results suggested a potential mechanism by which proinflammatory monocytes could promote AMD pathology.

In contrast to the findings above, Oliver et $a l^{30}$ did not find evidence of differential methylation between AMD cases and age-matched controls and they concluded that hypomethylation within the ILI7RC gene promoter in peripheral blood is not suitable for use as a clinical biomarker of AMD, highlighting the need for considerable replication of epigenetic association studies before clinical application.

\section{DNA methylation and histone acetylation status may affect AMD pathogenesis via the inhibition of angiogenesis and inflammation}

Clusterin/apolipoprotein J (apo J), a multifunctional secreted chaperone, is one of the major proteins in drusen that are protein aggregates deposited between RPE and Bruch's membrane in AMD. ${ }^{31,32}$ Clusterin also participates in cholesterol transport and is present in high-density lipoprotein complexes in human plasma, ${ }^{33}$ and for that reason, clusterin is sometimes called apo J. Clusterin and vitronectin are the complement regulatory proteins that can bind to the membrane attack complexes and prevent cytolysis. The deficiency of these complement inhibitors might aggravate inflammation and provoke the exudative phase of AMD. The promoter of clusterin contains a CpG-rich methylation domain. As aging affects both DNA methylation and histone acetylation status, the epigenetic regulation might have an important role in clusterin/apo J expression. DNMT and histone deacetylase (HDAC) inhibitors are potent angiostatic agents, inhibiting angiogenesis both in vitro and in vivo. HDAC inhibitors are characterized as inhibitors of angiogenesis, and clusterin as a complement inhibitor. Epigenetic therapy with DNMT and HDAC inhibitors are currently being evaluated in clinical trials for cancer. ${ }^{34}$ Trichostatin A is a potent HDAC inhibitor that evokes histone hyperacetylation and induces selective gene transcription. ${ }^{35,36}$

Suuronen $e a^{37}$ observed that treatments with DNMT and HDAC inhibitors induced prominent increases in the expression levels of clusterin mRNA and protein in ARPE-19 cells, as well as in the secretion of clusterin protein. Furthermore, they observed that valproic acid, recently shown to inhibit the activity of HDACs, ${ }^{38}$ induced a significant increase in clusterin protein expression and secretion in retinal pigment epithelial cells. Their results indicate that epigenetic factors regulate clusterin expression in RPE cells. This might affect the pathogenesis of AMD via the inhibition of angiogenesis and inflammation. Although the role of clusterin in the pathogenesis of AMD is largely unknown, as a complement inhibitor, it might protect against inflammation and reduce neovascularization.

Additionally, Crosson et al ${ }^{39}$ demonstrated that HDAC inhibitors can significantly reduce retinal injury initiated by ischemia/reperfusion. This retinal protective action was associated with the suppression of retinal tumor necrosis factor- $\alpha$ (TNF- $\alpha)$ expression. In vitro studies provided evidence that HDAC inhibitors can also inhibit the downstream action of TNF- $\alpha$, suppressing the increases in matrix metalloproteinases associated with TNF- $\alpha$ receptor stimulation. These findings support the idea that the regulation of acetylation in the retina provides a viable neuroprotective strategy for the treatment of retinal diseases in which ischemia may have a role in the etiology of the disease, such as in wet AMD.

\section{Hypoxia-inducible factors and chromatin remodeling in AMD}

The cellular response to hypoxia is largely dependent on changes in gene expression, which are mainly commanded by a unique family of transcription factors named HIFs, for hypoxia-inducible factors. ${ }^{40-41} \mathrm{HIFs}$ are heterodimeric transcription factors composed of a constitutively expressed HIF- $1 \beta$ subunit and one of three oxygen-sensitive $\alpha$-subunits (HIF1A, HIF2A, or HIF3A). ${ }^{42,43}$ HIF- $\alpha$ subunits are hydroxylated in two key prolyl residues by specific prolyl hydroxylases (PHD1, PHD2, 
and PHD3). ${ }^{44-46}$ When cells become hypoxic, hydroxylation is inhibited and HIF starts to accumulate.

Although HIF1 is expressed by a single gene, HIF1 $A$, ${ }^{47}$ the transcription of the gene is not affected by oxygen showing that regulation of HIF takes place primarily at the posttranslational level.

Stress-induced changes in gene expression are accompanied by or are a result of changes in chromatin structure; however, the relationship between hypoxiaregulated alterations of chromatin and downstream effects on transcription is addressed in relatively few studies. ${ }^{48}$ Johnson et al ${ }^{49}$ found that hypoxia causes widespread repression of total RNA and mRNA synthesis, independently of HIF-1, and globally induces a mixture of histone modifications, typically associated with either transcriptional activation or repression.

Oxidative stress has been implicated in the senescence of RPE cells and pathogenesis of AMD; it occurs when the level of ROS, such as free radicals, hydrogen peroxide, and singlet oxygen, exceeds the detoxifying capacity of antioxidants or molecular chaperones (a large group of unrelated protein families whose role is to stabilize unfolded proteins, to prevent inappropriate association or aggregation of exposed hydrophobic surfaces and direct their substrates into productive folding, transport, or degradation pathways), especially in the retina, where the production of ROS is high. ${ }^{50-54}$ It appears clear that ROS and HIF are directly involved in stimulating angiogenesis, both in tumors and in the retina. ${ }^{55,56}$

Intermittent hypoxia, followed by reoxygenation, has been shown to determine the production of ROS, which may lead to HIF activation and accelerated aging and to the appearance of age-related diseases. ${ }^{57}$

ROS increases HIF protein expression and prevents the hydroxylation of HIF-1a protein. This results in the elicited transcriptional activity. ${ }^{58,59}$ These molecular responses ultimately lead to the increased expression of vascular endothelial growth factor (VEGF) that is the predominant growth factor-stimulating choroidal neovascularization (CNV) in exudative AMD. ${ }^{60}$

Although different aspects of HIF regulation are well known, it is still unclear by which precise mechanism HIFs activate transcription of their target genes. Efforts are being made to understand how various complement cascade-associated gene polymorphisms affect hypoxiasensitive elements and the retinal pathology. Local inflammatory and immune-mediated events are involved in the development of drusen, although the precise cellular mechanisms need to be studied. ${ }^{61-63}$ A variety of inflammatory cells, including macrophages, fibroblasts, mast cells, histiocytic, and giant cells, have been found in the choroid and in isolated choroidal neovascular membranes of eyes suffering from advanced AMD emphasizing their important contribution to AMD pathogenesis. ${ }^{64-67}$

Hypoxia provokes a marked decrease of general transcription that seems to rely in part on epigenetic changes through a poorly understood mechanism.

Transcriptional activation of the HIF1A upregulates the expression of VEGF in general and in RPE cells. It is thus a central molecule for triggering CNV formation and has therefore been proposed as a promising novel therapeutic target in the treatment of CNV in exudative AMD. Further results are required to establish the potency of this interesting molecule as a therapeutic target in AMD treatments. ${ }^{68}$

\section{Non-coding RNA (microRNA)-mediated gene regulation in AMD}

\section{Regulation of gene expression by microRNAs is implicated in choroidal neovascularization}

Over the past few decades, microRNAs (miRNAs) have emerged as a prominent class of gene regulators. miRNAs are endogenous small, single-strand noncoding RNAs of about 22 nucleotides. ${ }^{69}$ miRNA functions as a guide molecule in posttranscriptional gene silencing. Base pairing between miRNA and mRNA leads to translational repression or mRNA degradation. ${ }^{70}$

By regulating numerous mRNAs, miRNAs have a key role in a wide range of physiologic and pathologic processes. ${ }^{71,72}$ Accumulating evidence indicates that aberrant miRNA expression profiles are observed in a variety of cancers. Several specific miRNAs control blood vessel formation, such as miR-126. ${ }^{73}$ Aberrant angiogenesis leads to a variety of pathologies such as cancer, ischemia, psoriasis, and AMD.

Sabatel et $a l^{74}$ first performed in vitro experiments to test the involvement of miR-21 in angiogenesis and they found that miR-21 overexpression impairs angiogenesis in vitro. Using different in vitro angiogenic assays, they demonstrated that miR-21 overexpression affects endothelial cell proliferation, migration, and organization into tubes. MiR-21 was also found to modify actin cytoskeleton organization. The same investigators demonstrated in vivo the therapeutic efficacy of miR-21 overexpression in reducing angiogenesis in a model of pathologic CNV. To evaluate the impact of miR-21 in vivo in pathologic angiogenesis, they used a laser-induced murine model of $\mathrm{CNV}$, which mimics AMD pathology. ${ }^{75}$ Intravitreal injection of premiR-21 or the control molecule was performed just after laser burns. Seven days after Bruch's membrane rupture at four locations, the mice were injected with fluoresceinlabeled dextran and the eyes were removed and mounted for microscopic analysis. The CNV at the 
Bruch's membrane rupture sites was quantified by area. A marked reduction in blood vessel density in animals treated with pre-miR was noted. These results indicate the therapeutic efficacy of miR-21 induction in pathologic angiogenesis. Few angiogenic inhibitors have been used in therapy and they have failed to produce an enduring clinical response in most patients. Their low efficacy is notable because of the appearance of resistance mechanisms, as these inhibitors are specific for a single angiogenic receptor. ${ }^{76,77}$ Therefore, the ability of one miRNA to target multiple mRNAs represents an attractive potential therapeutic approach.

Shen et $\mathrm{l}^{78}$ used microarray analysis to identify miRNAs that are upregulated or downregulated in ischemic retina. Three miRNAs were confirmed to be substantially reduced in ischemic retina by real-time PCR and the effect of intraocular injection of these miRNAs was tested on levels of products of target genes and on neovascularization. Candidate target genes were identified for three downregulated miRNAs: Pdgfb and Hif1 $\alpha$ for miR-31, Vegf and Pdgfb for miR-150, and Frizzled4 for miR-184. Compared with injection of a control pre-mi, injection of premiR-31 into the eyes of mice with ischemic retinopathy caused significant reductions in platelet-derived growth factor-B (PDGF-B) and HIF- $1 \alpha$, confirming that they are targets for miR-31. In a similar manner, VEGF and PDGF-B were confirmed to be targets for miR-150. Interestingly, they found that injection of premiR-31 also reduced VEGF in ischemic retina, which must occur indirectly, possibly through reduction of HIF-1a, because VEGF is not a target for miR-31. HIF-1a is a transcriptional activator of VEGF that is responsible for increased VEGF levels in ischemic retina. ${ }^{79,80}$ The target genes that have been identified for miR-31 and -150 code for proteins that have proangiogenic activity, which provides reasonable mechanisms of action for inhibition of neovascularization achieved by injection of these miRNAs. The ability of miRNAs to alter simultaneously levels of several gene products in the angiogenesis cascade, and their role as part of an endogenous control system that could potentially be manipulated, suggest that they may be valuable in the development of new treatments for neovascular AMD.

\section{MiRNAs as regulators of macular RPE cell survival in response to oxidative stress}

Numerous studies have demonstrated that miRNAs are involved in the regulation of cell survival in response to oxidative stress. ${ }^{81,82}$ RPE cell damage, induced by high levels of ROS, has an important role in the pathogenesis of AMD. ${ }^{83-86}$ Exposure of cells to oxidant generators elicits changes in the expression of multiple genes, and these changes are responsible for ROS-mediated RPE cell death and apoptosis. ${ }^{87-89}$ The extrinsic apoptosis pathway is activated by apoptosis-inducing ligands, such as the Fas ligand..$^{90}$ Increased Fas expression in AMD photoreceptors has been found in eyes with exudative AMD and in those with geographic atrophy (GA). ${ }^{91}$

Lin $e t a l^{92}$ evaluated the miR-23a expression level in $A M D$, and the interaction between miR-23a and apoptotic factor, such as Fas in oxidative stress, was determined.

First, they identified that miR-23a expression was downregulated in macular RPE cells from AMD patients compared with normal donors. Second, they showed that forced overexpression of miR-23a reduced cell death induced by hydrogen peroxide. The protective effect of miR-23a was blocked by miR-23a inhibition. Finally, they identified that miR-23a binds to the $3^{\prime}$-untranslated region of Fas, an apoptotic factor involved in ROSmediated cell death. Downregulation of Fas by miR-23a could help protect RPE cells from oxidative damage. For the first time, they showed an antiapoptotic effect of miR-23a against oxidative injury and the expression changes of miR-23a could be very important in ROS-mediated cell death/survival and gene expression.

Their results clearly indicate that miR-23a has an important role in cytoprotection of RPE cells by prevention of apoptosis. The protection of RPE cells against oxidative damage is afforded by miR-23a through the regulation of Fas, which may be a novel therapeutic target in retinal degenerative diseases.

\section{MiRNAs as regulators of the inflammatory process, an important factor in the pathogenesis of AMD}

A normal functioning RPE is indispensable for vision. RPE dysfunction, resulting from chronic inflammation, is an important factor in the pathogenesis of AMD. ${ }^{93}$ Ocular inflammation is often associated with the infiltration of lymphocytes and macrophages to the posterior compartment of the eye and their secretion of inflammatory mediators such as IFN- $\gamma, \mathrm{TNF}-\alpha$, and IL-1. ${ }^{94,95}$ These inflammatory cytokines can target the RPE and seriously impair its many critical functions.

MiRNAs, by their ability to target messenger RNAs for degradation or translational repression, are known to regulate inflammatory responses. ${ }^{96}$ Many genes including $B A C H 1, S H I P 1, C E B P B$, and $I K K \varepsilon$ are targeted for translational repression by miR-155. ${ }^{97-100}$ Kutty et al ${ }^{101}$ investigated the miRNA expression in human $\mathrm{RPE}$ cells in response to treatment with inflammatory cytokines IFN- $\gamma, \mathrm{TNF}-\alpha$, and IL- $1 \beta$. They showed that inflammatory cytokines increase miR-155 expression in human RPE cells. They also demonstrated that the Janus family kinases/signal transducers and activators of 
transcription signaling pathway could be directly involved in the regulation of miR-155 expression. RPE cell perturbation resulting from chronic inflammation is thought to be a major factor in the development of AMD. ${ }^{93}$ Thus, miR-155, because of its inherent ability to regulate inflammatory processes, could have a key role in the pathogenesis of AMD. miR-155 has the potential to modulate the response of the RPE cells to inflammatory stimuli and, therefore, this miRNA may serve as a target for therapeutic intervention in retinal diseases such as uveitis and AMD.

Complement factor $\mathrm{H}(\mathrm{CFH})$ is an important member of the regulator of complement activation (RCA) group of proteins. The brain and retina may have an independent CFH supply secreted by neurons, astroglia, microglial, and/ or endothelial cells. ${ }^{102-104} \mathrm{CFH}$ expression is significantly downregulated in the degenerating brain and retina, suggesting that insufficient quantities of this RCA regulator lead to excessive activation of the innate immune response and proinflammatory signaling. ${ }^{105-117}$

There are many shared pathologic characteristics of Alzheimer's disease (AD) and AMD, including decreases and/or dysfunction in $\mathrm{CFH} .{ }^{118} \mathrm{CFH}$ inhibits alternative pathway activation both in plasma and on cell surfaces by promoting $\mathrm{C} 3 \mathrm{~b}$ proteolysis. ${ }^{108}$ This pathway is strongly implicated in AMD risk, as several components are either present in diseased tissues, such as the characteristic extracellular drusen deposits (CFH, C3b/ $\mathrm{iC} 3 \mathrm{~b}, \mathrm{BF}$, and $\mathrm{C} 5 \mathrm{~b}-9)$, or they are genetically associated with disease risk $(C 3, C 2 / B F, C F H, C F H R 1, C F H R 3$, and CFI). ${ }^{119-123}$ miRNA-mRNA pairings have been strongly selected over evolution to maximize their efficiency in regulating brain and retinal gene expression, as well as expression in other tissues. Lukiw et al ${ }^{118}$ recently showed that upregulation of brain- and retinal-abundant miRNAs, including miRNA-9, miRNA-125b, miRNA146a, and miRNA-155, are common to the pathogenetic mechanism of $\mathrm{CFH}$ deficiency that drives inflammatory neurodegeneration, which is characteristic of both AD and AMD. They speculated that a subfamily of human miRNAs that include miRNA-125b, miRNA-146a, miRNA-155, and perhaps miRNA-9 and others may help coordinate innate immune and inflammatory signals across the entire anteroposterior axis of the retinalprimary visual cortex pathway, and perhaps also in other immunoresponsive cells and tissues. They suggested that anti-miRNA therapeutics could be developed for the effective management of these diseases.

The miRNA-processing enzyme DICER1 is reduced in the RPE of humans with GA inducing Alu RNA toxicity

DNA that does not code for proteins represents $98 \%$ of our genome. ${ }^{124}$ This intronic non-coding DNA contains regulatory elements that control gene expression. A variety of diverse elements are needed for posttranscriptional regulation of gene expression. They are located mainly in the untranslated regions of mRNAs, where they control the diverse posttranscriptional processes, such as RNA editing or modification (such as methylation). Transposons are considered generally as non-coding DNA, although they can mediate structural changes and they can affect expression of genes by numerous ways. A transposable element (transposon or retrotransposon) can change its position within the genome. The most common transposable elements are called Alu genetic elements that can induce mutations by inserting near or within genes. If such mutations are confined to non-coding regions, they have little discernible impact on the bearer. Alu insertions are however sometimes disruptive and can result in inherited disorders (cancer types).

Kaneko et al ${ }^{125}$ showed that the miRNA-processing enzyme DICER1 is reduced in the RPE of humans with GA, and conditional ablation of Dicer1, but not seven other miRNA-processing enzymes, induces RPE degeneration in mice. Their findings suggested that the principal biologic effect of DICER1 deficit contributing to the development of GA is not miRNA dysregulation. However, this does not exclude miRNA dysregulation promoting GA through other pathways. Their findings elucidate a critical cell survival function for DICER1 by functional silencing of toxic $A l u$ transcripts. The ability of Alu RNA antisense oligonucleotides to inhibit DICER1 depletion-induced RPE cytotoxicity provides a rationale to investigate $A l u$ RNA inhibition or DICER1 augmentation as potential therapies for GA.

\section{Conclusions and future directions}

It has been said that calculating the risk based on combination of all risk allele seems more appropriate than using single susceptibility genes variants as a predictive value for $\mathrm{AMD}$, but this requires robust estimates of risk scores for each of the associated loci. ${ }^{126}$ A major challenge lies in understanding the functional significance of the variants, their relationship with each other and to epigenetic and environmental contributions. Recently, the Encyclopedia of DNA Elements (ENCODE) project has systematically mapped regions of transcription, transcription factor association, chromatin structure, and histone modification. These data provide biochemical functions for $80 \%$ of the genome, in particular outside of the well-studied protein-coding regions ${ }^{127}$ (http:/ / www. genome.gov/10005107). Next-generation sequencing technologies and the use of high-resolution genome-wide epigenetic profiles offer high-throughput approaches that promise a more complete understanding of the functional 


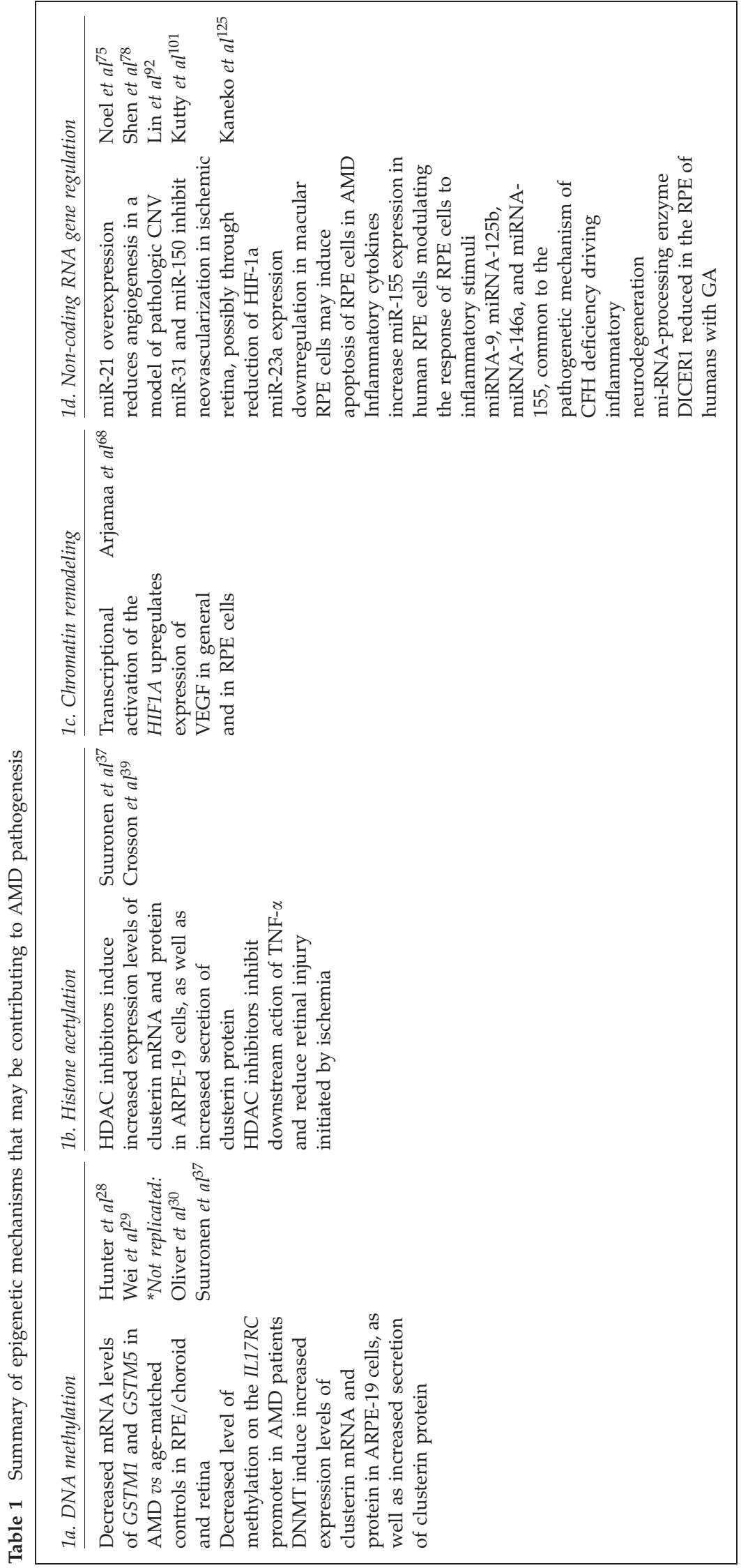


impact of epigenetics, that is, large-scale epigenetic studies of disease-discordant monozygotic twins who are completely matched for genetics, age, sex, cohort effects, maternal influences, and common environment, and are closely matched for other environmental factors, may be considerably more powerful in detecting disease-related epigenetic differences than epigenetic studies of unrelated disease cases and controls with different life histories. ${ }^{12}$

A significant obstacle in investigating the impact of epigenetic mechanisms in AMD is that we need access to the tissue we are interested in to study processes such as methylation. This is difficult for the eye as we cannot easily access eye tissues such as the retina except post mortem. Possibly, generating eye tissues such as RPE from patient-derived stem cells may allow such investigations in the future.

Although the complete extent to which epigenetic changes contribute to AMD is unknown, the papers referenced in this review provide tantalizing evidence that epigenetic changes do contribute to AMD (Table 1).

Any therapeutic intervention for AMD that addresses an isolated pathogenetic mechanism is unlikely to address the impact of multiple complex pathways that lead to the development of the disease. This review highlights the important role epigenetics has in human disease, and it emphasizes the need to study the role of epigenetics in AMD pathogenesis in the future.

\section{Conflict of interest}

The authors declare no conflict of interest.

\section{References}

1 He S, Li X, Chan N, Hinton DR. Review: epigenetic mechanisms in ocular disease. Mol Vis 2013; 19: 665-674.

2 Liu MM, Chan CC, Tuo J. Genetic mechanisms and age-related macular degeneration: common variants, rare variants, copy number variations, epigenetics, and mitochondrial genetics. Hum Genom 2012; 6: 13.

3 Sobrin L, Seddon JM. Nature and Nurture-genes and environment-predict onset and progression of macular degeneration. Prog Retin Eye Res 2014; 40: 1-15.

4 Whitcup SM, Sodhi A, Atkinson JP, Holers VM, Sinha D, Rohrer B et al. The role of the immune response in age-related macular degeneration. Int J Inflam 2013; 2013: 348092.

5 Stefánsson E, Geirsdóttir A, Sigurdsson H. Metabolic physiology in age related macular degeneration. Prog Retin Eye Res 2011; 30: 72-80.

6 Payne AJ, Kaja S, Sabates NR, Koulen P. A case for neuroprotection in ophthalmology: developments in translational research. Mol Med 2013; 110: 429-436.

7 Hjelmeland LM. Dark matters in AMD genetics: epigenetics and stochasticity. Ophthalmol Vis Sci 2011; 52: 1622-1631.
8 Mazzio EA, Soliman KF. Basic concepts of epigenetics: impact of environmental signals on gene expression. Epigenetics 2012; 7: 119-130.

9 Adams J. Imprinting and genetic disease: Angelman, Prader-Willi and Beckwith-Weidemann syndromes. Nat Educ 2008; 1: 129.

10 Waddington CH. The epigenotype. 1942. Int J Epidemiol 2012; 41: 10-13.

11 Hunter DJ. Gene-environment interactions in human diseases. Nat Rev Genet 2005; 6: 287-298.

12 Bell J, Spector T. A twin approach to unraveling epigenetics. Trends Genet 2011; 27: 116-125.

13 Manolio TA, Collins FS, Cox NJ, Goldstein DB, Hindorff LA, Hunter DJ et al. Finding the missing heritability of complex diseases. Nature 2009; 461: 747-753.

14 Boumber Y, Issa JP. Epigenetics in cancer: what's the future? Oncology 2011; 25: 220-226, 228.

15 Valinluck V, Tsai HH, Rogstad DK, Burdzy A, Bird A, Sowers LC. Oxidative damage to methyl-CpG sequences inhibits the binding of the methyl-CpG binding domain (MBD) of methyl-CpG binding protein 2 (MeCP2). Nucleic Acids Res 2004; 32: 4100-4108.

16 Zhu WG, Srinivasan K, Dai Z, Duan W, Druhan LJ, Ding H et al. Methylation of adjacent $\mathrm{CpG}$ sites affects Sp1/Sp3 binding and activity in the p21(Cip1) promoter. Mol Cell Biol 2003; 23: 4056-4065.

17 Chen RZ, Pettersson U, Beard C, Jackson-Grusby L, Jaenisch R. DNA hypomethylation leads to elevated mutation rates. Nature 1998; 395(6697): 89-93.

18 Jones PA. Functions of DNA methylation: islands, start sites, gene bodies and beyond. Nat Rev Genet 2012; 13: 484-492.

19 Allfrey VG, Faulkner R, Mirsky AE. Acetylation and methylation of histones and their possible role in the regulation of RNA synthesis. Proc Natl Acad Sci USA 51: 786-794.

20 AREDS report no. 8. A randomized, placebo-controlled, clinical trial of high-dose supplementation with vitamins $C$ and $\mathrm{E}$, beta carotene, and zinc for age-related macular degeneration and vision loss. Ophthalmology 2001; 119: 1417-1436

21 Gu X, Meer SG, Miyagi M, Rayborn ME, Holoyfield JG, Grabb JW et al. Carboxyethylpyrrole protein adducts and autoantibodies, biomarkers for age-related macular degeneration. J Biol Chem 2003; 278: 42027-42035.

22 Ates O, Azizi S, Alp HH, Kiziltunk A, Beydemir S, Cinici E et al. Decreased serum paraoxonase 1 activity and increased serum homocysteine and malondialdehyde levels in age-related macular degeneration. Tohoku J Exp Med 2009; 217: 17-22.

23 Friedman DS, O'Colmain BJ, Munoz B, Tomany SC, McCarty C, de Jong PT et al. Prevalence of age related macular degeneration in the United States. Arch Ophthalmol 2004; 122: 564-572.

24 Buch H, Vinding T, la Cour M, Jensen GB, Prause JU, Nielsen NV. Risk factors for age-related maculopathy in a 14-year follow-up study: the Copenhagen City Eye Study. Acta Ophthalmol Scand 2005; 83: 409-418.

25 Smith W, Assink J, Klein R, Mitchell P, Klaver CC, Klein BE et al. Risk factors for age-related macular degeneration: pooled findings from three continents. Ophthalmology 2001; 108: $697-704$. 
26 Frederick JM, Rayborn ME, Laties AM, Lam DM, Hollyfield JG. Dopaminergic neurons in the human retina. J Comp Neurol 1982; 210: 65-79.

27 Hyman LG, Lilienfeld AM, Ferris III, FL, Fine SL. Senile macular degeneration: a case-control study. Am J Epidemiol 1983; 118: 213-227.

28 Hunter A, Spechler PA, Cwanger A, Song Y, Zhang Z, Ying GS et al. dna methylation is associated with altered gene expression in AMD. IOVS 2012; 53: 2089-2105.

29 Wei L, Liu B, Tuo J, Shen D, Chen P, Li Z et al. Hypomethylation of IL17RC promoter associates with age related macular degeneration. Cell Rep 2012; 1151-1158.

30 Oliver VF, Franchina M, Jaffe AE, Branham KE, Othman M, Heckenlively JR et al. Hypomethylation of the IL17RC promoter in peripheral blood leukocytes is not a hallmark of age-related macular degeneration. Cell Rep 2013; 5: 1527-1535.

31 Crabb JW, Miyagi M, Gu X, Shadrach K, West KA, Sakaguchi $\mathrm{H}$ et al. Drusen proteome analysis: an approach to the etiology of age-related macular degeneration. Proc Natl Acad Sci USA 2002; 99: 14619-14621.

32 Anderson DH, Mullins RF, Hageman GS, Johnson LV. A role for local inflammation in the formation of drusen in the aging eye. Am J Ophthalmol 2002; 134: 411-431.

33 Jenne DE, Lowin B, Peitsch MC, Bottcher A, Schmitz G, Tschopp J. Clusterin (complement lysis inhibitor) forms a high density lipoprotein complex with apolipoprotein A-I in human plasma. J Biol Chem 1991; 266: 11030-11036.

34 Hellebreker DM, Griffoen AW, Van Engeland M. Dual targeting of epigenetic therapy in cancer. Biochim Biophys Acta 2007; 1775: 76-91.

35 Nakao M. Epigenetics: interaction of DNA methylation and chromatin. Gene 2001; 278: 25-31.

36 Yoshida M, Horinouchi S, Beppu T. Trichostatin A and trapoxin: novel chemical probes for the role of histone acetylation in chromatin structure and function. Bioessays 1995; 17: 423-430.

37 Suuronen T, Nuutinen T, Ryhänen T, Kaarniranta K, Salminen A. Epigenetic regulation of clusterin/ apolipoprotein J expression in retinal pigment epithelial cells. Biochem Biophys Res Commun 2007; 357: 397-401.

38 Goettlicher M, Minucci S, Zhu P, Krámer OH, Schimpf A, Giavara $S$ et al. Valproic acid defines a novel class of HDAC inhibitors inducing differentiation of transformed cells. EMBO J 2001; 20: 6969-6978.

39 Crosson CE, Mani SK, Husain S, Alsarraf O, Menick DR. Inhibition of histone deacetylase protects the retina from ischemic injury. Invest Ophthalmol Vis Sci 2010; 51: 3639-3645.

40 Maxwell PH, Pugh CW, Ratcliffe PJ. Inducible operation of the erythropoietin $3^{\prime}$ enhancer in multiple cell lines: evidence for a widespread oxygen-sensing mechanism. Proc Natl Acad Sci USA 1993; 90: 2423-2427.

41 Wang GL, Semenza GL. General involvement of hypoxiainducible factor 1 in transcriptional response to hypoxia. Proc Natl Acad Sci USA 1993; 90: 4304-4308.

42 Semenza GL. HIF-1, O(2), and the 3 PHDs: How animal cells signal hypoxia to the nucleus. Cell 2001; 107: 1-3.

43 Bruick RK. Oxygen sensing in the hypoxic response pathway: regulation of the hypoxia-inducible transcription factor. Genes Dev 2003; 17: 2614-2623.

44 Bruick RK, McKnight SL. A conserved family of prolyl4-hydroxylases that modify HIF. Science 2001; 294: 1337-1340.
45 Epstein AC, Gleadle JM, McNeill LA, Hewitson KS, O'Rourke J, Mole DR et al. C. elegans EGL-9 and mammalian homologs define a family of dioxygenases that regulate HIF by prolyl hydroxylation. Cell 2001; 107: 43-54.

46 Schofield CJ, Ratcliffe PJ. Oxygen sensing by HIF hydroxylases. Nat Rev Mol Cell Biol 2004; 5: 343-354.

47 Iyer NV, Leung SW. The human hypoxia-inducible factor 1alpha gene: HIF1A structure and evolutionary conservation. Genomics 1998; 52: 159-165.

48 Johnson AB, Barton MC. Hypoxia-induced and stressspecific changes in chromatin structure and function. Mutat Res 2007; 618: 149-162.

49 Johnson AB, Denko N, Barton MC. Hypoxia induces a novel signature of chromatin modifications and global repression of transcription. Mutat Res 2008; 640: 174-179.

50 Marshall J. The ageing retina: physiology or pathology. Eye (Lond) 1987; 1: 282-295.

51 Winkler BS, Boulton ME, Gottsch JD, Sternberg P. Oxidative damage and age-related macular degeneration. Mol Vis 1999; 5: 32.

52 Decanini A, Nordgaard CL, Feng X, Ferrington DA, Olsen TW. Changes in select redox proteins of the retinal pigment epithelium in age-related macular degeneration. Am J Ophthalmol 2007; 143: 607-615.

53 Loane E, Kelliher C, Beatty S, Nolan JM. The rationale and evidence base for a protective role of macular pigment in age-related maculopathy. $\mathrm{Br} J$ Ophthalmol 2008; 92: 1163-1168.

54 Kaarniranta K, Salminen A, Eskelinen EL, Kopitz J. Heat shock proteins as gatekeepers of proteolytic pathwaysimplications for age-related macular degeneration (AMD). Ageing Res Rev 2009; 8: 128-139.

55 Al-Shabrawey M, Rojas M, Behzadian A, El-Remessay A, Bartoli M, Parpia AK et al. Role of NADPH in retinal inflammation. Invest Ophthalmol Vis Sci 2008; 49: 3239-3244.

56 Ushio-Fukai M, Nakamura Y. Reactive oxygen species and angiogenesis: NADPH oxidase as target for cancer therapy. Cancer Lett 2008; 266: 37-52.

57 Rapino C, Bianchi G, Di Giulio C, Centurione L, Cacchio M, Antonucci A et al. HIF-1alpha cytoplasmic accumulation is associated with cell death in old rat cerebral cortex exposed to intermittent hypoxia. Aging Cell 2005; 4: 177-185.

58 Frede S, Berchner-Pfannschmidt U, Fandrey J. Regulation of hypoxia-inducible factors during inflammation. Methods Enzymol 2007; 435: 405-419.

59 Yuan G, Nanduri J, Khan S, Semenza GL, Prabhakar NR. Induction of HIF-1alpha expression by intermittent hypoxia: involvement of NADPH oxidase, $\mathrm{Ca}^{2+}$ signaling, prolyl hydroxylases, and mTOR. J Cell Physiol 2008; 217: 674-685.

60 Schlingemann RO. Role of growth factors and the wound healing response in age-related macular degeneration. Graefes Arch Clin Exp Ophthalmol 2004; 242: 91-101.

61 Johnson LV, Leitner WP, Staples MK, Anderson DH. Complement activation and inflammatory processes in drusen formation and age related macular degeneration. Exp Eye Res 2001; 73: 887-896.

62 Hageman GS, Luthert PJ, Victor Chong NH, Johnson LV, Anderson DH, Mullins RF. An integrated hypothesis that considers drusen as biomarkers of immune mediated processes at the RPE-Bruch's membrane interface in aging and age-related macular degeneration. Prog Retin Eye Res 2001; 20: 705-732. 
63 Donoso LA, Kim D, Frost A, Callahan A, Hageman G. The role of inflammation in the pathogenesis of age-related macular degeneration. Surv Ophthalmol 2006; 51: 137-152.

64 Penfold PL, Killingsworth MC, Sarks SH. Senile macular degeneration: the involvement of immunocompetent cells. Graefes Arch Clin Exp Ophthalmol 1985; 223: 69-76.

65 Killingsworth MC, Sarks JP, Sarks SH. Macrophages related to Bruch's membrane in age-related macular degeneration. Eye 1990; 4: 613-621.

66 Hutchinson AK, Grossniklaus HE, Capone A. Giant-cell reaction in surgically excised subretinal neovascular membrane. Arch Ophthalmol 1993; 111: 734-735.

67 Seregard S, Algvere PV, Berglin L. Immunohistochemical characterization of surgically removed subfoveal fibrovascular membranes. Graefes Arch Clin Exp Ophthalmol 1994; 232: 325-329.

68 Arjamaa O, Nikinmaa M, Salminen A, Kaarniranta K. Regulatory role of HIF-1a in the pathogenesis of agerelated macular degeneration (AMD). Ageing Res Rev 2009; 8: 349-358.

69 Kim VN, Han J, Siomi MC. Biogenesis of small RNAs in animals. Nat Rev Mol Cell Biol 2009; 10: 126-139.

70 Pillai RS, Bhattacharyya SN, Filipowicz W. Repression of protein synthesis by miRNAs: how many mechanisms? Trends Cell Biol 2007; 17: 118-126

71 Li M, Li J, Ding X, He M, Cheng SY. MicroRNA and cancer. AAPS J 2010; 12: 309-317.

72 Zhang C. MicroRNAs in vascular biology and vascular disease. J Cardiovasc Transl Res 2010; 3: 235-240.

73 Nicoli S, Standley C, Walker P, Hurlstone A, Fogarty KE et al. MicroRNA-mediated integration of haemodynamics and Vegf signalling during angiogenesis. Nature 2010; 464: 1196-1200.

74 Sabatel C, Malvaux L, Bovy N, Deroanne C, Lambert V, Gonzalez ML et al. MicroRNA-21 exhibits antiangiogenic function by targeting RhoB expression in endothelial cells. PLoS One 2011; 6: e16979.

75 Noel A, Jost M, Lambert V, Lecomte J, Rakic JM. Anti-angiogenic therapy of exudative age-related macular degeneration: current progress and emerging concepts. Trends Mol Med 2007; 13: 345-352.

76 Bergers G, Hanahan D. Modes of resistance to antiangiogenic therapy. Nat Rev Cancer 2008; 8: 592-603.

77 Abdollahi A, Folkman J. Evading tumor evasion: current concepts and perspectives of anti-angiogenic cancer therapy. Drug Resist Updat 2010; 13: 16-28.

78 Shen J, Yang X, Xie B, Chen Y, Swaim M, Hackett SF et al. MicroRNAs regulate ocular neovascularization. Mol Ther 2008; 16: 1208-1216.

79 Ozaki H, Yu A, Della N, Ozaki K, Luna JD, Yamada H et al. Hypoxia inducible factor- $1 \mathrm{a}$ is increased in ischemic retina: temporal and spatial correlation with VEGF expression. Invest Ophthalmol Vis Sci 1999; 40: 182-189.

80 Kelly BD, Hackett SF, Hirota K, Oshima Y, Cai Z, Berg-Dixon $S$ et al. Cell type-specific regulation of angiogenic growth factor gene expression and induction of angiogenesis in nonischemic tissue by a constitutively active form of hypoxia-inducible factor 1. Circ Res 2003; 93: 1074-1081.

81 Cheng Y, Liu X, Zhang S, Lin Y, Yang J, Zhang C. MicroRNA-21 protects against the $\mathrm{H}(2) \mathrm{O}(2)$-induced injury on cardiac myocytes via its target gene PDCD4. J Mol Cell Cardiol 2009; 47: 5-14.
82 Tang Y, Zheng J, Sun Y, Wu Z, Liu Z, Huang G. MicroRNA-1 regulates cardiomyocyte apoptosis by targeting Bcl-2. Int Heart J 2009; 50: 377-387.

83 Winkler BS, Boulton ME, Gottsch JD, Sternberg P. Oxidative damage and age-related macular degeneration. Mol Vis 1999; 5: 32.

84 Hollyfield JG. Age-related macular degeneration: the molecular link between oxidative damage, tissuespecific inflammation and outer retinal disease: the Proctor lecture. Invest Ophthalmol Vis Sci 2010; 51: 1275-1281.

85 Cai J, Wu M, Nelson KC, Sternberg Jr, P, Jones DP. Oxidantinduced apoptosis in cultured human retinal pigment epithelial cells. Invest Ophthalmol Vis Sci 1999; 40: 959-966.

86 Kim MH, Chung J, Yang JW, Chung SM, Kwag NH, Yoo JS. Hydrogen peroxide-induced cell death in a human retinal pigment epithelial cell line, ARPE-19. Korean J Ophthalmol 2003; 17: 19-28.

87 Weigel AL, Handa JT, Hjelmeland LM. Microarray analysis of $\mathrm{H}_{2} \mathrm{O}_{2}-, \mathrm{HNE}-$, or tBH-treated ARPE-19 cells. Free Radic Biol Med 2002; 33: 1419-1432.

88 Pocrnich CE, Liu H, Feng M, Peng T, Feng Q, Hutnik CM. P38 mitogen-activated protein kinase protects human retinal pigment epithelial cells exposed to oxidative stress. Can J Ophthalmol 2009; 44: 431-436.

89 Zareba M, Raciti MW, Henry MM, Sarna T, Burke JM. Oxidative stress in ARPE-19 cultures: do melanosomes confer cytoprotection? Free Radic Biol Med 2006; 40: 87-100.

90 Ashkenazi A, Dixit VM. Apoptosis control by death and decoy receptors. Curr Opin Cell Biol 1999; 11: 255-260.

91 Dunaief JL, Dentchev T, Ying GS, Milam AH. The role of apoptosis in age-related macular degeneration. Arch Ophthalmol 2002; 120: 1435-1442.

92 Lin H, Qian J, Castillo AC, Long B, Keyes KT, Chen G et al. Effect of miR-23 on oxidant-induced injury in human retinal pigment epithelial cells. Invest Ophthalmol Vis Sci 2011; 52: 6308-6314.

93 Nussenblatt RB, Liu B, Li Z. Age-related macular degeneration: an immunologically driven disease. Curr Opin Invest Drugs 2009; 10: 434-442.

94 Hooks JJ, Chan CC, Detrick B. Identification of the lymphokines, interferon-gamma and interleukin-2, in inflammatory eye diseases. Invest Ophthalmol Vis Sci 1988; 29: 1444-1451.

95 Cousins SW, Espinosa-Heidmann DG, Csaky KG. Monocyte activation in patients with age related macular degeneration: a biomarker of risk for choroidal neovascularization? Arch Ophthalmol 2004; 122: 1013-1018.

96 Sonkoly E, Pivarcsi A. microRNAs in inflammation. Int Rev Immunol 2009; 28: 535-561.

97 Tili E, Michaille JJ, Cimino A, Costinean S, Dumitru CD, Adair B et al. Modulation of miR-155 and miR-125b levels following lipopolysaccharide/TNF-alpha stimulation and their possible roles in regulating the response to endotoxin shock. J Immunol 2007; 179: 5082-5089.

98 Costinean S, Sandhu SK, Pedersen IM, Tili E, Trotta R, Perrotti D et al. Src homology 2 domain-containing inositol-5-phosphatase and CCAAT enhancer-binding protein beta are targeted by miR-155 in B cells of Emicro-MiR-155 transgenic mice. Blood 2009; 114: 1374-1382.

99 O'Connell RM, Chaudhuri AA, Rao DS, Baltimore D. Inositol phosphatase SHIP1 is a primary target of miR-155. Proc Natl Acad Sci USA 2009; 106: 7113-7118. 
100 Skalsky RL, Samols MA, Plaisance KB, Boss IW, Riva A, Lopez MC et al. Kaposi's sarcoma-associated herpesvirus encodes an ortholog of miR-155. J Virol 2007; 81: 12836-12845.

101 Kutty RK, Nagineni CN, Samuel W, Vijayasarathy C, Hooks JJ, Redmond TM. Inflammatory cytokines regulate microRNA-155 expression in human retinal pigment epithelial cells by activating JAK/STAT pathway. Biochem Biophys Res Commun 2010; 402: 390-395.

102 Zipfel PF, Lauer N, Skerka C. The role of complement in AMD. Adv Exp Med Biol 2010; 703: 9-24.

103 Cui JG, Kuroda H, Chandrasekharan NV, Pelaez RP, Simmons DL, Bazan NG et al. Cyclooxygenase-3 gene expression in Alzheimer hippocampus and in stressed human neural cells. Neurochem Res 2004; 29: 1731-1737.

104 Zeiss CJ. Animals as models of age-related macular degeneration: an imperfect measure of the truth. Vet Pathol 2010; 47: 396-413.

105 Kondo N, Bessho H, Honda S, Negi A. Complement factor HY402H variant and risk of agerelated macular degeneration in Asians: a systematic review and meta-analysis. Ophthalmology 2011; 118: 339-344.

106 Takata K, Kitamura Y. Molecular approaches to the treatment, prophylaxis, and diagnosis of Alzheimer's disease: tangle formation, amyloid- $\beta$ peptides, and microglia in Alzheimer's disease. J Pharmacol Sci 2012; 118: 331-337.

107 Cui JG, Hill JM, Zhao Y, Lukiw WJ. Expression of inflammatory genes in the primary visual cortex of latestage Alzheimer's disease. NeuroReport 2007; 18: 115-119.

108 Ohno-Matsui K. Parallel findings in age-related macular degeneration and Alzheimer's disease. Prog Retina Eye Res 2011; 30: 217-238

109 Ramkumar HL, Zhang J, Chan CC. Retinal ultrastructure of murine models of dry age-related macular degeneration (AMD). Prog Retin Eye Res 2010; 29: 169-190.

110 Telander DG. Inflammation and age-related macular degeneration (AMD). Semin Ophthalmol 2011; 26: 192-197.

111 Lukiw WJ, Dua P, Pogue AI, Eicken C, Hill JM. Up-regulation of micro RNA-146a (miRNA-146a), a marker for inflammatory neurodegeneration, in sporadic Creutzfeldt-Jakob disease (sCJD) and Gerstmann-Straussler Scheinker (GSS) syndrome. I Toxicol Environ Health 2011; 74: 1460-1468.

112 Pogue AI, Percy ME, Cui JG, Li YY, Bhattacharjee S, Hill JM et al. Upregulation of NF-kB-sensitive miRNA-125b and miRNA-146a in metal sulfate-stressed human astroglial (HAG) primary cell cultures. J Inorganic Biochem 2011; 105: 1434-1437.

113 Lukiw WJ, Zhao Y, Cui JG. An NF-kB-sensitive micro RNA-146a-mediated inflammatory circuit in Alzheimer disease and in stressed human neural cells. I Biol Chem 2008; 283: 31315-31322.

114 Li YY, Alexandrov PN, Pogue AI, Zhao Y, Bhattacharjee S, Lukiw WJ. miRNA-155 upregulation and complement factor H (CFH) deficits in Down's syndrome. NeuroReport 2012; 23: 168-173.

115 Lukiw WJ, Alexandrov PN. Regulation of complement factor $\mathrm{H}(\mathrm{CFH})$ by multiple miRNAs in Alzheimer's disease brain. Mol Neurobiol 2012; 46: 11-19.

116 Barile GR, Schmidt AM. RAGE and its ligands in retinal disease. Curr Mol Med 2007; 7: 758-765.

$117 \mathrm{Xu}$ S. MicroRNA expression in the eyes and their significance in relation to functions. Prog Retin Eye Res 2009; 28: 87-116.

118 Lukiw WJ, Surjyadipta B, Dua P, Alexandrov PN. Common micro RNAs (miRNAs) target complement factor $\mathrm{H}$ (CFH) regulation in Alzheimer's disease (AD) and in agerelated macular degeneration (AMD). Int J Biochem Mol Biol 2012; 3: 105-116.

119 Ansari M, Mckeigue PM, Skerka C, Heyward C, Rudan I, Vitart V et al. Genetic influences on plasma $\mathrm{CFH}$ and CFHR1 concentrations and their role in susceptibility to age-related macular degeneration. Hum Mol Genet 2013; 22: 4857-4869.

120 Montezuma SR, Sobrin L, Seddon JM. Review of genetics in age related macular degeneration. Semin Ophthalmol 2007; 22: 229-240.

121 Hageman GS, Luthert PJ, Victor Chong NH, Johnson LV, Anderson DH, Mullins RF. An integrated hypothesis that considers drusen as biomarkers of immune-mediated processes at the RPE-Bruch's membrane interface in aging and age-related macular degeneration. Prog Retin Eye Res 2001; 20: 705-732.

122 Scholl HP, Fleckenstein M, Charbel Issa P, Keilhauer C, Holz FG, Weber BH. An update on the genetics of agerelated macular degeneration. Mol Vis 2007; 13: 196-205.

123 Ennis S, Gibson J, Cree AJ, Collins A, Lotery AJ. Support for the involvement of complement factor I in age-related macular. Eur I Hum Genet 2010; 18: 15-16.

124 Ule J. Alu elements: at the crossroads between disease and evolution. Biochem Soc Trans 2013; 41: 1532-1535.

125 Kaneko H, Dridi S, Tarallo V, Gelfand BD, Fowler BJ, Cho WG. DICER1 deficit induces Alu RNA toxicity in agerelated macular degeneration. Nature 2011; 471: 325-330.

126 Ratnapriya R, Chew EY. Age-related macular degeneration-clinical review and genetics update. Clin Genet 2013; 84: 160-166.

127 Bernstein BE, Birney E, Dunham I, Green ED, Gunter C, Snyder M. ENCODE Project Consortium: an integrated encyclopedia of DNA elements in the human genome. Nature 2012; 489: 57-74. 